\title{
Breathe Easy? Local Nuances of Authoritarian Environmentalism in China's Battle against Air Pollution
}

\author{
Anna L. Ahlers ${ }^{*}$ and Yongdong Shen ${ }^{\dagger, *}$
}

\begin{abstract}
The heavy smog suffocating China's cities is increasingly being perceived as a threat by both the population and the authorities. Consequently, political action aiming at regulating ambient air pollution has become increasingly comprehensive and rigid in recent years. Even measures limiting consumption and production seem to become acceptable as China is facing an airpocalypse. Does this suggest a genesis of real "authoritarian environmentalism" (AE) in China? Taking this as a heuristic point of departure, we present findings from research on the implementation of air pollution control measures in Hangzhou city. We offer a critical examination of the concept of AE and, in particular, of local policy implementation strategies vis-à-vis the general public. Two measures in Hangzhou's air policy portfolio are analysed that reveal considerable variation: restrictions on the use of private cars and the (re)location of industrial facilities. Describing the conditions that have helped to produce different implementation strategies, we argue for different emphases in a potential Chinese model of AE. In a context where outcomes are sought at any cost, we observe more complexity and nuances than are usually captured by the AE concept.
\end{abstract}

Keywords: China's local governance; authoritarian environmentalism; air pollution prevention and control policy; private car use restrictions; industrial resettlement

Effective ecological, climate and resource protection policies usually entail painful cuts in individual consumption and require sober revisions of all kinds of growth patterns. The concept of "authoritarian environmentalism" (hereafter abbreviated to AE) concedes that, in theory, authoritarian governments are better equipped with institutional and procedural features that allow for faster and

* University of Oslo.

$\dagger$ University of Oslo and Zhejiang University. Email: yongdongshen@zju.edu.cn (corresponding author).

\$ These two authors contributed equally to this work, and share lead authorship. 
more rigorous responses to environmental problems than are possible in democracies. In the words of Bruce Gilley,

(...) authoritarian environmentalism can be provisionally defined as a public policy model that concentrates authority in a few executive agencies manned by capable and uncorrupt elites seeking to improve environmental outcomes. Public participation is limited to a narrow cadre of scientific and technocratic elites while others are expected to participate in state-led mobilization for the purposes of implementation. The policy outputs that result include a rapid and comprehensive response to the issue and usually some limits on individual freedoms. ${ }^{1}$

It is argued (and expected) that "modern" authoritarian regimes, with a problem-focused eco-elite group, a policy-bound professional bureaucracy, and the rigid means to sanction individual behaviour, have the ability to rapidly implement sweeping programmes and wide-ranging measures. In the case of the People's Republic of China (PRC), Bruce Gilley later made two specific amendments:

First, even with executive authority concentrated, implementation becomes highly dispersed in a large, decentralized system; in modern governance, much policy will be made at these downstream stages. Secondly, even when public participation is narrowly defined in official frameworks, there may be considerable mid-level activism within those narrow boundaries. Society does not become dormant even in an authoritarian model, but merely shifts its involvement towards acceptable areas. ${ }^{2}$

However, many other observers contend that the hailed effectiveness, or "authoritarian clout," of national-level environmental policymaking is usually offset by this very "dispersion of implementation." Under the auspices of the Chinese political system, they argue, local bureaucracies are often not incentivized enough to safeguard the comprehensive implementation of environmental policies. ${ }^{3}$ Even advocates of Chinese AE, who have tried to trace it (primarily) in the field of climate politics, have come to the conclusion that, although policy responses have become increasingly swift and government activism (output) has been heightened during the last decade, actual results (outcomes) are still lacking. ${ }^{4}$

In this article, we do not intend to evaluate, from a macroscopic point of view, whether China's mode of governance functions exceptionally well or badly when it comes to tackling environmental challenges; rather, our study has been inspired by empirical observations in the field of air pollution ${ }^{5}$ prevention and control policies (hereafter, "air policy"). First of all, we take the basic assumptions ingrained in the concept of AE very seriously - especially those formulated for China by Beeson and by Gilley ${ }^{6}$ - and examine these in the contexts in which they might be expected to play out most drastically, i.e. in the final processes of local policy implementation. In particular, we concentrate on one of the key

3 Kostka 2016; Kostka and Eaton 2014; Ran Ran 2015.

4 Beeson 2010; Gilley 2012.

5 This study concentrates on "air pollution" as it is usually defined in a popular and political context in China. As the introduction to this special issue has explained, the type of air pollution that is currently receiving most attention is atmospheric particulate pollution. Greenhouse gas emissions, i.e. climate change politics, etc., are usually treated separately. See, also, Ahlers and Hansen 2017.

6 Beeson 2015; Gilley 2012. 
assumptions of AE that has, as yet, been surprisingly underresearched in the case of China: how environmental policies are made and measures are implemented by local authorities in consideration of, vis-à-vis, or "against" the general public at the local level. The concept of AE implies the almost complete exclusion of public discussion on the input side, the authoritarian manner in which individual freedoms are targeted and restricted on the output side, and the state-led mobilization of relevant public parties for the sake of effective final policy implementation. ${ }^{7}$ How this works in practice and the level of complexity this involves from a local state perspective has not yet been subjected to thorough study.

This article aims to fill the gap by refining some of the key aspects of Chinese AE presented in the existing literature. We emphasize that there are significant nuances of Chinese $\mathrm{AE}$ at the local level, and draw attention to the conditions on the ground as well as to the strategies chosen by local authorities that have helped to produce them. Interestingly enough, we find that the choices on the continuum between coercive and more consultative means followed a rather counter-intuitive pattern: the more urgent and risky the conditions were perceived to be (i.e. the need for quick solutions which would affect the majority of the citizens, implying the potential risk of discontent and possibly "social destabilization"), the harsher and more exclusive were the strategies adopted by local implementers. In contrast, for more selective measures within a broader time frame, local authorities included the public in order to ensure smooth implementation and to deal with the often complex stakeholder relations and conflicts involved. However, we consider the more inclusive nuances of AE as still not necessarily equivalent to the features of "consultative authoritarianism" that are described in recent China studies literature. In both cases, although willing to accommodate limited public participation and opinions, the Chinese Communist Party (CCP) reserves the right to make the final decisions. But whereas the latter notion usually denotes a more open mode of searching for solutions, which includes the consultation or participation of the public or specific actors at the decision-making and formulation stage, ${ }^{8}$ sometimes even the outsourcing of policy tasks to civic or corporate actors, ${ }^{9} \mathrm{AE}$ implies that a sacrosanct political authority takes the decisions it deems necessary to meet urgent environmental problems that are difficult to reach in a public and participatory manner and only allows for some flexibility, maybe participation, when it comes to effectively implementing them.

Taking a microscopic approach to AE in the field of air policies, we have conducted three rounds of fieldwork in Hangzhou city, Zhejiang province, and its surroundings since autumn 2014. The data collection method followed an

7 See, also, Beeson 2015, 523. These measures can therefore be expected to go beyond the usual toolbox of environmental politics (e.g. Sterner and Coria 2012). Except for more coercive means than just merely legal sanctioning, they may also include more informal means of incentivizing.

8 He and Thøgersen 2010, Truex 2014.

9 Teets 2013. 
approach employed for exploratory case studies, which included 41 semistructured interviews with leading representatives of Party and government departments at the provincial and municipal levels, environmental NGOs, scholars (most notably in the fields of public administration, bio-chemistry and environmental engineering), local business representatives, neighbourhood committees and individual residents, as well as an analysis of work reports and official documents at the central, provincial and city levels, site visits and a review of the relevant survey and research literature.

The article is organized as follows: the next section presents arguments for the new implications of the air pollution problem for the concept of AE in China in general. The article then zooms in on the local level, to Hangzhou city in Zhejiang province. We provide a brief introduction to the prevailing situation in Hangzhou and the basic pillars of the municipal governments' ambitious air policy, and then focus on two very different measures in Hangzhou city's local air policy portfolio that reveal considerable variation in the associated implementation strategies and the interfaces occurring between local authorities and the public: the city's attempts to curb motor vehicle driving and the (re)location of air-polluting industries. Altogether, a diverse picture emerges which, in conclusion, leads us to suggest some amendments to the AE concept in order to clarify what is actually on display in China's "modern" authoritarian approach to tackling these environmental challenges.

\section{China's Airpocalypse - Driver of Reloaded Authoritarian Environmentalism?}

Public surveys show that environmental pollution and, in particular, "air pollution" are among the top issues of concern among the Chinese population, and usually only second to "corruption." 10 And although it is difficult to perceive any sort of silver lining in the thick blankets of smog, certain trends have emerged during the last few years that are worth mentioning. Air pollution control and prevention has become a crucial item on the Chinese governments' agenda, as is manifest, for example, in the national Action Plan on Prevention and Control of Air Pollution, the recently revised Air Pollution Prevention and Control Law, and the very recently promulgated 13th Five-Year Plan (20162020). Leading Party and government cadre evaluation now includes environmental indicators such as air quality, ${ }^{11}$ while political propaganda and public

10 Wike, Richard, and Bridget Parker. 2015. "Corruption, Pollution, Inequality Are Top Concerns in China. Pew Research Center - Global Attitudes and Trends," 24 September, http://www.pewglobal. org/2015/09/24/corruption-pollution-inequality-are-top-concerns-in-china/. Accessed 01 October 2015. See, also, Li and Tilt 2017 (in this issue).

11 Ministry of Environmental Protection of the People's Republic of China (MEP). 2013. "Zhongzubu yinfa tongzhi gaijin zhengji kaohe gongzuo. Jiada huanjing sunhai deng zhibiao quanzhong" (Central Organization Department issues notice on the revision of evaluation work. Increases the weighting of environmental harm as a criterion). 11 December, http://edcmep.org.cn/hjxw/5762.html. Accessed 26 June 2015. 
education has been fortified to evoke the spirit of "since we breathe together, we must also fight together." 12

Although a comprehensive assessment of the results is not yet possible, these efforts have already had some initial tangible effects on particulate air pollution in China. ${ }^{13}$

China's air pollution problem is slowly but surely receding, new data shows. More than three years on from its infamous "airpocalypse," China's pollution levels are dropping at an average rate of $12 \%$ a year following emergency government action. ${ }^{14}$

Interestingly enough, in most of the related reports, analysts have attributed these fledgling successes to the harsh measures undertaken as part of the new governmental initiative and not only to the continuing economic slowdown and reduced production levels. ${ }^{15}$ Could this all be taken as an indication that China's airpocalypse, with the reactions that this has provoked from the government and society, has the potential to be a game changer in China's environmental policy?

\section{Societal perception and political framing of the air pollution problem}

The perception and framing of problems are crucial elements of China's seemingly becoming $\mathrm{AE}$ in practice. Arguably, air pollution represents an environmental problem that actually meets the preconditions for "authoritarian responses" better than those previously described in the relevant literature on China. It embodies a challenge that both the general population and the authorities face in much more specific and immediate ways than the rather more diffuse threat of climate change which was the focal point of former analyses. For reasons of limited space, ${ }^{16}$ we will here emphasize only some of the characteristic aspects of air pollution as a perceived problem, including the ensuing social and political reactions to these that are of specific relevance for our description of Chinese $\mathrm{AE}$ in dialogue with the existing portrayals. Gilley and, to a lesser extent, Beeson, ${ }^{17}$ point to the general lack of problem awareness and related "pressure to act" among the population as well as the lax policy mission and enforcement in the political system that, up to now, have rendered China's AE less than effective. It does not take much to argue that the story is somewhat different when it comes to the problem of air pollution.

First of all, the impact of the recent fear of the effects of ambient air pollution on Chinese society as a whole is remarkable. Seen as a health risk that can affect each individual member of society, air pollution now transgresses the usual

12 Luo Sha et al. 2013.

13 See also the introduction to this special issue by Aunan, Hansen and Wang 2017.

14 Boren 2015.

15 AFP. 2015. "Air Pollution Levels Drop in China: Greenpeace,” Daily Mail Online, 21 April, http:/l www.dailymail.co.uk/wires/afp/article-3048298/Air-pollution-levels-drop-China-Greenpeace.html. Accessed 15 October 2015.

16 For a more detailed analysis of major events and shifts in policy-making concerning ambient air pollution in China, see Ahlers and Hansen 2017.

17 Gilley 2012; Beeson 2015. 
boundaries between rulers and the ruled, policymakers and policy addressees. These societal irritations can sometimes bear strange fruit: "smog" (wumai 雾霾) and " $\mathrm{PM}_{2.5}$ " have become "winged words" among the young and old, ${ }^{18}$ and everyday activities are often planned according to what mobile phone apps declare to be "good air" or "bad air" days. Although air pollution has not yet triggered large-scale public unrest or inspired a nationwide environmental movement in China, local communities have become increasingly aware of their rights and now demand increased environmental and health protection. ${ }^{19}$ At the same time, during the last decade the Chinese political authorities have shown themselves to be increasingly sensitive and responsive to public concerns and, as has been documented, even purely verbal demands can turn into a driving force for political action. ${ }^{20}$ Anticipation of protest as well as general awareness that environmental problems can have a considerable effect on public health and China's economic performance should probably be regarded as the main drivers of governmental action against air pollution. We therefore hold that what is observable in China's air pollution drama supports Beeson's claim that "it is primarily domestic rather than international pressure that is forcing the Chinese government to act, as it is compelled to address the reality of a degraded environment that represents a failure of its developmental model and the leaders who guide it." 21

It seems that ambient particulate pollution, and the immediate challenges and effects this brings in terms of visibility and health, strongly influence the perception of the situation by both the Chinese population and the authorities. Unlike the general climate protection framework, air quality protection requires local authorities to undertake measures against a complex problem that is much more immediate and graspable. Ambient air pollution's relative "measurability" in the context of performance evaluation ${ }^{22}$ also pushes them to present quick and significant results. Air pollution reduction thus became a topic of national concern, a campaign which required local adjustment and activism even before it was formally and legally upgraded by the central government's action plan for the prevention and control of air pollution in 2013 and the accompanying revised law this year. By vigorously working to find ways to anticipate crucial and highpriority policies, and adding innovative features to enhance their local effectiveness, leaders of sub-national governments are usually able to make a name for themselves. ${ }^{23}$ These dynamic adjustments and extensions are among the main

18 See Ahlers and Hansen 2017, and Li and Svarverud 2017 (this issue).

19 See, also, Hansen and Liu 2017 (this issue).

20 Lewis-Beck, Tang and Martini 2014; Wang 2008.

21 Beeson 2015, 528.

22 Environmental indicators are increasingly included in governments' target responsibility contracts and were recently strengthened in the leading cadre evaluation system, Caixin online. 2015. "China "to Hold Officials Accountable for Life for Environmental Problems," 13 August 2015, http://english.caixin.com/ 2015-05-08/100807608.html. Accessed 10 October 2015.

23 Ahlers and Hansen 2017. 
causes of the policy variation that is, to a remarkably high degree, observable in the field of local air policy implementation across China.

Finally, as our case studies will show, in order to implement often contested measures under the umbrella of air policy, local authorities benefited from the fact that these could be framed as inevitable necessities that had to be undertaken against a widely and publicly perceived environmental threat. Everything considered, we would go as far as to hypothesize that the intensification of eco-environment-related anxieties, accompanied by other social-engineering and educational means, can lead to the increased use and greater acceptance of topdown decision-making and more draconian implementation mechanisms in China.

\section{In Focus: Hangzhou City under the Dome ... and Searching for Ways Out}

For a study of the local implementation of China's new air policies, Hangzhou presents itself as a particularly interesting case for the following reasons: firstly, it is the capital of China's wealthiest province and features a well-developed economy with a strong service sector largely based on tourism. Hangzhou city can therefore "afford" - and is specially motivated - to clean up its air, and to manifest its green, "ecologically civilized" and "low-carbon" city image with nationwide appeal. ${ }^{24}$ Secondly, the city correspondingly represents a high level of socioeconomic development with, among other things, one of China's most highly ranked universities (Zhejiang University), a thriving NGO community, innumerable IT start-ups and a growing, cosmopolitan middle class and upper class.

Hangzhou's poor air quality has long troubled its inhabitants as well as tainted the city's reputation as a beautiful destination for tourism. Recreation and air pollution countermeasures were put in place even before the launch of the national action plan for the prevention and control of air pollution. For instance, since 2007, a number of air polluting enterprises in Hangzhou have been required to shut down or relocate - and in 2016, not least because of preparations for the G20 summit meeting in September, this work is even being extended. More specifically, since 2012, Annual Implementation Schemes for Combined Air Pollution Prevention (hereafter "Annual Scheme") have set targets for reducing nitrogen oxide emissions, and have underwritten actions such as controlling the consumption of coal and other energy sources, motor vehicle exhaust emissions, industrial air pollution, urban dust, rural straw burning, and cooking oil fumes emissions.

Following the promulgation of China's new national Atmospheric Pollution Prevention Action Plan (APAP) in 2013, Hangzhou city government published its own "Action Plan on Prevention and Control of Air Pollution in Hangzhou (2014-2017)." It raised the target to a decrease in $\mathrm{PM}_{10}$ of more than 10 per cent and to a decrease in $\mathrm{PM}_{2.5}$ of more than 26 per cent by 2017, as measured 
on the basis of figures calculated for $2013 .{ }^{25}$ After a preliminary evaluation of the performance, a 2014 Annual Scheme was launched that called for the relocation of yet another group of enterprises and the scrapping of polluting motor vehicles. This scheme also included the goal of improving the city's air quality index (AQI) by 9 per cent as compared with that of 2013. ${ }^{26}$ The 2015 Annual Scheme further aimed to achieve a reduction in $\mathrm{PM}_{2.5}$ of at least 9.1 per cent during the course of only one year.

In addition to publishing new ambitious targets almost every year, Hangzhou's government representatives also take pride in the fact that their emissions control indicators and evaluation targets have always been stricter than those laid down in central guidelines as well as those employed by other cities in China - a narrative that was supported by observers and local researchers. ${ }^{27}$ In its evaluation of subordinate government levels, Hangzhou goes one step further and allocates maximum points only if 70 per cent of the days during a one-year period have been classified as being of "excellent" or "good" air quality. Achieving less than 45 per cent means obtaining zero points in this target category. ${ }^{28}$ Hangzhou city government also introduced public surveys as part of the annual performance evaluation procedures. In the 2014 survey, the "management of air pollution" ranked first among the topics to which respondents wanted the city government to be more responsive. ${ }^{29}$

Air quality measurements conducted (or contracted) by superior-level evaluators are now increasingly seen as hard facts in China - notwithstanding all the whitewashing of data and the opacity that may still prevail especially vis-à-vis the public. While causes and effects are not always traceable and reproducible, this performance indicator creates stress among the relevant government bureaucracies and results in a great deal of serious activism in the search for effective smog-fighting tools. ${ }^{30}$ It is therefore not surprising that a rather obvious drop in total $\mathrm{PM}_{2.5}$ measures in 2014 led, literally, to gasps of relief in Hangzhou's environmental bureaucracy and among city leaders. ${ }^{31}$ This improvement provided a kick-start on the road towards achieving the city's three-year APAP goals, although the reasons for the decrease (scientifically speaking) cannot be directly related to specific types of short-term government intervention over the period of just one year. ${ }^{32}$

25 Hangzhou City Government 2014a.

26 An "Air Quality Index" combines measurements of major ambient air pollutants and standardizes monitoring of air pollution in China since 2012. See Aunan, Hansen and Wang 2017 (this issue).

27 Interviews, Hangzhou, 13 and 17 January 2015.

28 Interview with leading official from the Comprehensive Evaluation Office of Hangzhou City, Hangzhou, 13 March 2015.

29 Delman 2015.

30 Interview with officials from the Economic and Information Technology Commission of Hangzhou City, Hangzhou, 16 March 2015.

31 In general, during 2014, the average concentration of $\mathrm{PM}_{2.5}$ went down to, $64.6 \mu \mathrm{g} / \mathrm{m} 3(-7.7 \%)$ (Hangzhou EPB 2014). For the first three quarters of 2015, Greenpeace reported another drop of $11.7 \%$ in average $\mathrm{PM}_{2.5}$ concentration in Hangzhou.

32 Ahlers and Hansen 2017. 
As in most other Chinese cities, analyses conducted by Hangzhou city's Environmental Protection Bureau had identified motor vehicle exhaust and industrial emissions as the two primary and consistent sources of $\mathrm{PM}_{2.5}$ pollution. We shall now examine in greater detail two of the related core measures in the city's air policy portfolio, namely car ownership and driving controls and the relocation of polluting industries, in order to trace the nuances of local air policy implementation strategies.

\section{Nuances of Hangzhou City's Air Policy Implementation}

Case A: car policy - against all odds?

At noon, on 25 March 2014, the Hangzhou municipal government held a press conference to announce that the number of new car licence plates issued would from now on be limited and that this regulation would take effect just five hours after the announcement. Traffic authorities would not issue any new car licence plates until 25 April 2014, when a lottery and auction system for obtaining new licence plates would be launched. In addition, restrictions on vehicle use during the rush hour would be extended from 5 May in the same year.

What was behind this bold move? By the end of December 2011, the analysis of major $\mathrm{PM}_{2.5}$ sources by Hangzhou's Environmental Monitoring Centre had shown that motor vehicle exhaust emissions amounted to 39.5 per cent of the overall $\mathrm{PM}_{2.5}$ pollution in the urban areas of Hangzhou. The number of licensed cars in Hangzhou was already excessive, and was continuing to grow exponentially. By the end of April 2014, the number of motor vehicles had reached $1,897,527$, i.e. a further 18.11 per cent increase on the figure of $1,606,638$ in April 2013. This meant that Hangzhou ranked in first place in terms of cars per inhabitant (i.e. one car per three persons) and in seventh place out of the 36 main Chinese cities with the highest total numbers of private cars. ${ }^{33}$ One obvious result of this was heavy traffic congestion. In 2013, there were 35 days of serious traffic congestion with an average speed of below $20 \mathrm{~km} / \mathrm{h}$ during rush hours. ${ }^{34}$ These traffic jams, especially during peak times, were said to have resulted in an even greater level of vehicle exhaust emissions. Realizing the intrinsic contribution of motor vehicle emissions to particulate pollution, Hangzhou's municipal leadership decided to take immediate action, which meant, first and foremost, controlling the number of motor vehicles in the city in 2014. Backed by the Regulation for the Control of Motor Vehicle Exhaust Pollution in

33 Xinhua Net. 2014. "Hangzhou shishi xiaokeche zongliang tiaokong guanli, xiangou xianxing shuangchong cuoshi" (Hangzhou's implements control and regulation of small passenger cars: two measures for license limitation and traffic control), 25 March, http://finance.sina.com.cn/roll/20140325/ 195818610408.shtml. Accessed 16 October 2015.

34 Hangzhou Net. 2015. "Hangzhou shuangxian man yi nian, jiaotong daodi gaishan le duoshao?" (Traffic controls have been in effect in Hangzhou for one year now. How much did the traffic situation improve?), 11 May, http://ori.hangzhou.com.cn/ornews/content/2015-05/11/content_5765344.htm. Accessed 16 October 2015. 
Zhejiang province ${ }^{35}$ and the national APAP, this step seemed an effective way of reducing both air pollution and the city's immense traffic congestion problems.

Before the official announcement of Hangzhou's new policy, ${ }^{36}$ there had already been rumours about potential plans to limit the number of licence plates for new cars, but the local authorities had consistently denied them, so that when the new system was finally introduced in such an ad hoc fashion, a torrent of criticism was unleashed. City residents complained that the new Temporary Regulation for Control of the Number of Private Cars in Hangzhou ${ }^{37}$ had limited policy legitimacy since there had been neither notices to the public nor public hearings, which were by now a common feature in local drafting processes, and particularly widely used in Zhejiang province, before the policy was published. As such, this was found to violate the Rule for the Management of Administrative Regulatory Documents in Zhejiang Province, which, for instance, states that

in the process of drafting administration regulations, the local government must take advice from the public; for the issue of advancing significant public interests, the local government should organize forums and public hearings and listen to stakeholders' suggestions (...). ${ }^{38}$

In this case, however, without any "warning," Hangzhou city government had announced a completely new regulation. Consequently, Zhejiang provincial government was publicly called upon to scrap Hangzhou's new regulation before it became valid. Even official media outlets, such as Xinhua News, criticized the Hangzhou authority's sudden announcement, describing it as a "lose-lose situation," in which the city authorities had lost the citizens' trust and citizens had had to rush out to pay additional amounts of money in order to buy new cars in the remaining five hours before the deadline expired. ${ }^{39}$ Car dealers in Hangzhou confirmed during interviews that most of them had chosen to increase the price of cars just before the deadline came into effect. Nonetheless, many car salesrooms had to close down while others sought advice from colleagues in other cities, such as Beijing and Shanghai, where similar controls had been set up, and adjusted their business strategies accordingly. ${ }^{40}$

Against this chaotic backdrop, the Hangzhou city authorities saw themselves forced to provide some additional clarification, but continued to implement the decisions. According to a leading representative of Hangzhou city's Transportation Department,

35 Standing Committee of the People's Congress of Zhejiang Province 2013.

36 Only a few other cities across China had previously implemented similar controls of car ownership. Shanghai (2000), Beijing (2011), Guangzhou (2012) and Tianjin (2013) each introduced different systems for the obtainment of license plates, which basically meant auction or/and lottery. Hangzhou actually developed its strategy on the basis of the Tianjin model, combining a lottery and auction mode. See, also, Feng and $\mathrm{Li} 2013$.

37 Hangzhou City Government 2014b.

38 Zhejiang Provincial Government 2010.

39 Xinhua Net. 2014. "Hangzhou xianpai: benyi suihao, naihe shuangshu?" (License limitations in Hangzhou: while the original idea is good, is there not actually a double loss?), 27 March, http:// www.zj.xinhua.org/newscenter/headlines/2014-03/27/c_119964187.htm. Accessed 16 October 2015.

40 Interview with car sales manager, Hangzhou, 10 March 2015. 
limiting the number of car license plates issued was an administrative decision that we had to take this way. Had the government included the public to discuss the issue first, the number of new registered cars would have increased sharply in the meantime. But the purpose of the regulation was to reduce the number of new cars. ${ }^{41}$

The city government issued a public statement to the effect that there was nothing untoward concerning the legitimacy of the policy because it followed the Regulations for the Control of Motor Vehicle Exhaust Pollution in Zhejiang Province, which allows "municipal governments to take certain actions to control the number of motor vehicles in accordance with the city's conditions and size and the local air quality." 42 Concerning the problem of excluding the public throughout the policy drafting process, the same officer remarked further:

Yes, the public was right that the government should have heard the public's suggestions in hearings which are a must when publishing ordinary administration regulations. But it is also in the regulations by Zhejiang Province that the decision-making process can be simplified (jianhua zhiding chengxu 简化制定程序) in exceptional cases and for security reasons. That was what we followed. ${ }^{43}$

Later, however, after the announcement had been made, Hangzhou city government published a draft version of the Regulations for the Control of the Number of Private Cars in Hangzhou and invited public discussion on the details of vehicle control by post, fax, email and hotlines. But as a result the draft regulations were not meaningfully revised. On 29 April 2014, the city government finally promulgated the temporary regulations that set a limit on the number of licence plates issued, and which were supposed to be effective, first of all, for one year.

Hangzhou thus started to implement a multifaceted strategy by means of which it could control the number of licence plates issued (xianpai 限牌) and gradually scrap the old and heavily polluting, or "yellow sticker," vehicles (huangbiaoche 黄标车). Since 5th May 2014, restrictions have been imposed on car driving by means of a temporary ban on specific licence plate numbers (weihao xianxing 尾号限行) and non-Hangzhou registered vehicles. ${ }^{44}$ By these means, traffic in downtown areas is controlled during the weekday rush-hour periods and vehicular access to sightseeing and "ecological conservation" areas, e.g. around the West Lake, is constrained. As expected, the new traffic control measures in Hangzhou led to a slower increase in the number of new cars. Official figures revealed that the number of cars registered in Hangzhou during the first year of the new policy increased from 1,897,527 in April 2014 to 1,975,285 in April 2015. The growth rate was therefore cut by 14.01 per cent compared with that of 2013 (Table 1). Not surprisingly, this also had positive effects on the degree

41 Interview with leading official from the Transportation Department of Hangzhou City, Hangzhou, 10 March 2015.

42 Standing Committee of People's Congress of Zhejiang Province 2013.

43 Interview with leading official from the Transportation Department of Hangzhou City.

44 This means that, for example, cars with license plate digits ending with the numbers " 1 " and " 0 " are not allowed to drive in downtown areas between 7:00-9:00 a.m. and 4:30-6:30 p.m. on Mondays. On Tuesdays, this refers to license plate numbers ending in " 2 " and " 9 ", and so forth. 


\section{Table 1: Number and Growth Rate of Registered Cars in Hangzhou City}

\begin{tabular}{lcc}
\hline & $\begin{array}{c}\text { Total number of } \\
\text { registered cars }\end{array}$ & $\begin{array}{c}\text { Growth rate (based on the } \\
\text { figures from the previous year) }\end{array}$ \\
April 2013 & $1,606,638$ & - \\
April 2014 & $1,897,527$ & 18.11 per cent \\
April 2015 & $1,975,285$ & 4.10 per cent \\
April 2016 & $2,055,106$ & 4.04 per cent \\
Source: & \\
Official statistics, Hangzhou City Transportation Department, 2013-2016, http://xkctk.hzcb.gov.cn. Accessed 15 October 2016. \\
Note: \\
$\quad$ We extracted the data for the month of April for each year, since it was on 25 April 2014 that a lottery and auction system for \\
obtaining new licenses was launched in Hangzhou.
\end{tabular}

of traffic congestion and air pollution in the city. Measurements have shown that traffic regulations during rush hour also contribute to the reduction of air pollution, although vehicle emissions are still the main source of particulate pollution. ${ }^{45}$ Nevertheless, according to Hangzhou city's 2014 Environment Bulletin, the contribution of motor vehicle exhaust emissions to $\mathrm{PM}_{2.5}$ pollution was reduced to 28 per cent by the end of $2014 .{ }^{46}$

Altogether, measures to control vehicle emissions were implemented via a highly exclusive and centralized process. This is probably not overly surprising given that some interviewees referred to this policy innovation as a pet project of Zhejiang province's Party secretary. Once the decision was made that Hangzhou, as the provincial capital, should implement car usage restrictions in early 2014 , the relevant municipal government departments were only allowed about one month to garner information about the handful of other cities in China that had previously introduced similar measures and to draft implementation guidelines. Members of this task force were bound to the highest degree of confidentiality because of the extremely publicly contested nature of the project. ${ }^{47}$

At the time of our second visit in March 2015, the city government was in the process of revising the regulations after the first year. This was clearly still a highly sensitive issue for the city authorities, which was at the same time being subjected to intense pressure by both its superiors and the citizenry to improve public transportation and facilitate alternative or "greener" modes of motorized transportation, such as e-car rental or carpooling/sharing. Interestingly enough, despite the fact that the air pollution caused by diesel trucks, (mini)buses and other similarly-sized vehicles (as well as low-quality fuel in general) was publicly considered the main challenge to be tackled, restricting private car usage remained high on the political agenda.

45 The other major components are estimated to be industrial pollution (22.8\%), dust pollution (20.4\%), coal burning (18.8\%), and others (10\%) (Hangzhou City EPB 2014).

46 Hangzhou City EPB 2014.

47 Interview with leading official from the Traffic Police Department of Hangzhou City, Hangzhou, 9 March 2015. 
Finally, Hangzhou was not the last city government to take this rather risky step. Several of the strategies that were tested there, such as shortening the deadline between the date of the announcement and the date that the policy came into effect, restricting car sales during this period and strongly emphasizing the proportionately high contribution of vehicle exhaust emissions to air pollution in general, resulted in leaders from many other cities visiting Hangzhou on inspection tours. ${ }^{48}$ On 29 December 2014, Shenzhen city followed suit and declared that it would immediately limit the number of car licence plates being issued, again without having a public hearing, and without even announcing a deadline. ${ }^{49}$ Public protests against the measure were even louder in Shenzhen, but for Hangzhou at least, the anecdotal evidence that we were able to glean from residents indicated that the measures themselves are being gradually accepted with the passage of time because of a widely shared preference, not only for air quality improvement (a policy label that was mentioned by many interviewees) but also for congestion control. ${ }^{50}$ Public discontent prevails over the way that these policies are implemented and with the inconveniences they entail. ${ }^{51}$ However, even interviewees who had endured the frustrating experience of not being able to buy a car and drive it exactly how and when they wished, ${ }^{52}$ nevertheless had to agree that now everyone simply was obliged to contribute to improving the conditions in Hangzhou.

\section{Case B: public dialogue vis-à-vis air polluting industries}

By the end of 2006, the official data collected by the city Environmental Protection Bureau (hereafter EPB) showed that two older industrial regions in the urban areas of Hangzhou, the Banshan 半山 district and the Beidaqiao 北大桥 district, made up 80 per cent of the city's total coal consumption and produced more than 70 per cent of the total pollution emissions. ${ }^{53}$ Local residents appealed to government agencies and the media at different levels, and even collectively protested against the industrial air pollution in their

48 Interview with leading official from the Transportation Department of Hangzhou City, Hangzhou, 10 March 2015.

49 Nanfang dushibao (Southern Metropolis Daily). 2014. "Shenzhen tufa shuangxian ling" (Shenzhen announced to immediately limit the number of license plates issued), 30 December. http://paper. oeeee.com/nis/201412/30/312498.html. Accessed 16 October 2015.

50 This was also found by Chen and Zhao (2013) in a survey about public perception of Shanghai City's car licensing policy.

51 Horizon Key. 2015. "Shuzi jieshi 'xianxing buru jianliang"” (Numbers show "limits do not equal reduction”), 13 January, http://www.horizonkey.com/c/cn/news/2015-01/13/news_2633.html. Accessed 13 June 2015.

52 In the first year, from 1 May 2014, until 30 April 2015, the free lottery had an estimated success rate of $0.81-2.20 \%$. Bidding for a license plate cost up to 47,785 yuan, which amounted to about one-third of the average price of a 2014 FAW Volkswagen Golf in China, Zhejiang News. 2015. "Shenqing yao bu yao jiashi? Hangzhou xianpai zhengce jiang tiaozheng 4 yue 30 ri qian fabu xingui" (Driving license required for applications? New regulations published before Hangzhou's [car] licence limitation policy is adjusted on April 30), 13 March, http://zjnews.zjol.com.cn/system/2015/03/13/020550157.shtml. Accessed 21 May 2015.

53 Hangzhou EPB 2011, 13. 
neighbourhood. ${ }^{54}$ There were around 1,250 complaints addressed to Hangzhou city's EPB via hotlines, letters and visits in $2006 .{ }^{55}$ This conflict between local residents and polluting industries signified a potential risk to social stability and kept local authorities on high alert.

Following the Supervision and Management Measures for Environmental Pollution of Zhejiang Province, ${ }^{56}$ the Hangzhou city government promulgated a Comprehensive Environmental Pollution Regulation Scheme for the two districts, starting in $2007 .{ }^{57}$ The declared target was to reduce industrial air pollution by 80 per cent, relocate or shut down significantly polluting enterprises, and decrease the number of complaints made by local residents. However, putting these regulation schemes into action turned out to be far from straightforward and dragged on for years. Complications arose because many polluting plants were state-owned enterprises (SOEs) affiliated with local government agencies. For instance, one of them, the Wanli Chemical Factory, which produced washing powder, laundry detergent and liquid soap, was attached to Hangzhou's Economic and Information Technology Commission. Most of these companies had operated in the urban areas of Hangzhou for more than 40 years and had contributed significantly to the city's GDP. Any scheme to relocate or shut down these state-owned enterprises would, of course, not only lead to a reduction in local GDP growth, but would also face resistance from groups with a vested interest, as a leading official of Hangzhou city's EPB recalled:

the state-owned enterprises were supported by certain government departments and that entailed many obstacles for us. In addition, laid-off workers in state-owned enterprises were another big problem. ${ }^{58}$

In the meantime, problems began to escalate, especially in Wanjia Huacheng community, a residential area in Beidaqiao district, which had more than 2,600 apartments and primarily hosted members of medium- to high-income groups, including young office workers, local civil servants and businessmen. Most of the residents who had eagerly moved into these apartments in 2010 soon discovered that a noxious odour suffused the air where they were living. They quickly realized that this odour was actually due to the industrial waste gas emanating from the Wanli Chemical Factory, located in the northeast of the residential area, less than 200 metres away as the crow flies. By the end of 2010, 60 residents had spontaneously formed a self-help organization to protest against the level of industrial air pollution. In early 2011 this group even marched into Hangzhou's EPB to demand the closure of the chemical factory. ${ }^{59}$ Although the factory had been scheduled to relocate at the end of 2010, according to the Environmental

54 Interview with leading official from Hangzhou City’s EPB, Hangzhou, 22 March 2015.

55 Hangzhou EPB 2011, 57.

56 Zhejiang Provincial Government 2006.

57 Hangzhou EPB 2007; Hangzhou EPB 2009.

58 Interview with leading official of Hangzhou City's EPB.

59 Interview with former leader of the residents' self-help organization of Wanjia Huacheng community, Hangzhou, 16 July 2015. 
Pollution Comprehensive Regulation Scheme, the relocation had been delayed due to the difficulties involved in finding an alternative site. Discontented with being continuously exposed to polluted air, the residents started to criticize the lack of action taken by Hangzhou city's EPB, and petitioned the provincial government: "We didn't trust the local EPB anymore. We wanted to take collective action to draw the government leaders' attention and urge them to solve our problems". ${ }^{60}$ In May 2011, more than 30 residents of Wanjia Huacheng community blocked the main entrance of the chemical plant and presented banners addressed to the Hangzhou EPB.

Faced with local residents' lack of confidence in the official relocation plan, Hangzhou city's EPB, in order to mollify the anger of the public and to put pressure on the polluting SOEs to relocate or to shut down as soon as possible, decided to embark on a new strategy by implementing a kind of communication mechanism described as a "dialogue platform between enterprises and residents" (changqun duihua pingtai 厂群对话平台). Representatives of the Wanli Chemical Factory enterprise and local residents as well as government agencies affiliated with the enterprise were invited to take part in the dialogue. Residents were encouraged to express their complaints and demands, while the companies' executives were expected to provide them with answers and to come up with plans for the reduction of industrial air pollution. Government agencies in charge of the polluting enterprise had to promise to enforce controls, while representatives of the local EPB acted as facilitators and witnesses.

During the first round of dialogue on 16 August 2011, the Hangzhou EPB pledged to local residents that the Wanli Chemical Factory would be forced to end production if it could not be relocated. The manager of the factory announced that the new factory site was in Jiande 建德 county (in Hangzhou's jurisdiction) and that the company would invest 4,000,000 yuan to upgrade filters in order to reduce the discharge of pollutants. According to our interviewees, many of the local residents' representatives openly showed their disbelief and lack of trust. To ease the situation a little, the director of Hangzhou city's EPB disclosed his private cell phone number and invited residents to call him if they had any problems. For the second session, a check on the factory's performance was promised. As a trade-off, residents were asked to stop interfering with the factory's current operations.

The second round of dialogue was held on 10 September 2011. Representatives of the local community were invited to pay an inspection visit to the factory's new site in Jiande county for details of the completion date for the construction of the new site, etc. Upon seeing the site for the new factory, the residents reportedly felt somewhat relieved. But although it was under construction, the completion date was still a long way off and local residents were continuing to suffer the effects of the heavy pollution produced by the original plant. On 25 October 2011, a third

60 Interview with former leader of the residents' self-help organization of Wanjia Huacheng community. 
round of dialogue was held to try to deal with this problem. Local residents demanded that the factory, in order to reduce air pollution, should further reduce output. The local EPB, likewise, suggested that the factory should reduce production output or stop production during the night hours and at weekends when most of the residents were at home. The factory managers, for their part, complained that, with the aim of continuing production, they had invested a great deal of extra money to upgrade the filters just two months earlier and that they would not be able to reach their production target if they only worked during the day on weekdays alone. Finally, however, weighing the costs against the benefits, the factory gave way and accepted the local EPB's suggestion, promising to accelerate the relocation process with the support of specific government subsidies. The Wanli chemical plant was finally relocated to the new site in Jiande county at the beginning of 2012 .

In this way, Hangzhou's EPB completed its first set of "dialogue" sessions between an enterprise and the residents, and considered them a success. This led to the staging of further similar forums in the Banshan and the Beidaqiao districts: a thermal power plant was required to deal with the dark smoke coming out of its chimneys in early 2012, a steel plant was required to stop highly polluting production procedures in late 2012, and a chemical factory was shut down because of serious dust emissions in 2013. ${ }^{61}$ After 2014, this sort of dialogue mechanism was frequently adopted across the whole of Hangzhou municipality, not least because Hangzhou had launched a campaign to relocate all polluting industries from the city centre in preparation for the G20 summit in September 2016. Furthermore, Hangzhou's experience was mentioned in national media reports and similar attempts at resolving conflict over air pollution between local community residents and polluting enterprises that took place under the aegis of local authorities are observable in other Chinese cities since the 2010s. Most recently, in 2015, a township belonging to Shanghai city founded a "dialogue platform" to resolve a conflict over industrial air and water pollution and undertook policy enforcement measures with direct reference to the "Hangzhou model." 62

In Hangzhou, these dialogue mechanisms provided new channels through which the local authorities could distribute updated information about pollution regulations to aggrieved local residents and also use them as leverage to exert pressure on the problematic enterprises. This helped the government in its work towards achieving tangible policy results. By the end of 2012, the number of complaints made by local residents had fallen sharply to 413 , compared to

61 Hangzhou EPB 2013.

62 Shanghai Maqiao Township Government Website. 2015. "Dajian jiaoliu pingtai, huajie changqun maodun" (Staging a communication platform: conciliating conflicts between factories and the public). 20 May, http://www.shmq.gov.cn/sites/maqiaozhen/maqiaozhen_content.aspx?ctgid=d4894652-c1ca-4d189be9-63cc7bc3a5b3\&infoId=dee3e45e-f8a2-4c49-b020-0dc1a843203a. Accessed 16 October 2015. 
1,250 in $2006 .{ }^{63}$ A total of 450 enterprises were shut down or relocated between 2007 and 2013, 24 of which were state-owned enterprises affiliated to the Hangzhou municipal and Zhejiang provincial governments. ${ }^{64}$

\section{Conclusions: China's Authoritarian Environmentalism 2.0?}

China is trying to reduce levels of heavy air pollution on a tremendously large scale and within a limited time frame. Preliminary successes have already been achieved, although there might still be a very long way to go before any tangible and sustainable results can be gained. Our analysis was based on the notion that China's potential AE cannot be assessed by employing a macroscopic approach, but requires more detailed analysis where ultimate policy implementation happens, i.e. at the local level.

We began by observing that the focus on environmental problems in Chinese society has recently been intensified as a result of the heavy particulate air pollution in Chinese cities. By actually fulfilling more of the preconditions described in the usual AE concept than are found in climate change policies (in terms of the communication and perception of risks, the framing of countermeasures, the incentives for implementers, etc.), the air pollution problematique, arguably, gives China new momentum on its path towards developing an effective variant of AE.

Drawing on our studies of municipal-level "air policy" implementation, however, we have refined the Chinese AE narrative in certain respects. First, we would take issue with the argument about the apparent existence of a general divide between macro/national level effectiveness and micro/local level sabotage that has appeared in studies of Chinese AE so far. The two case studies that we have undertaken have shown how different agencies at municipal level came up with rather innovative steps under the banner of "air quality" policies. Indubitably, it was more often than not the national and provincial policies that lent legitimacy to the final implementation of contested measures, but the channels and varying effects of "dispersed implementation," in particular, downstream adaptability and flexibility under the aegis of $\mathrm{AE}$ in China, require further investigation.

Our primary aim, however, was to describe the style of air policy implementation vis-à-vis the population as well as the complexity involved from a local state perspective. With regard to car licensing and driving restrictions, which affected Hangzhou's society as a whole, we found that the local government deliberately chose a highly centralized and exclusive implementation mode. Interestingly

63 Hangzhou Net. 2013. "Liu nian zhengzhi, Banshan Beidaqiao diqu zhongdian wuran qiye huo guanting huo banqian" (Six years' of regulation: major polluting enterprises in Banshan and Beidaqiao districts were shut down or relocated), 28 November, http://hznews.hangzhou.com.cn/chengshi/content/2013-11/ 28/content_4981832.htm. Accessed 16 October 2015.

64 Hangzhou Daily. 2014. "Banshan yu Beidaqiao diqu wuran yao qingling, 2016 niandi zai guanting 7 jia daxing qiye" (Industrial pollution is projected to go down to zero in Banshan and Beidaqiao districts Another 7 large enterprises will be shut down at the end of 2016), 7 September, http://biz.zjol.com.cn/ system/2014/09/07/020243176.shtml. Accessed 16 October 2015. 
enough, notwithstanding the individual constraints and the dissatisfaction with governmental action that this gave rise to, the measures were apparently more acceptable to the public if labeled as "air quality protection" rather than as solutions to the problem of heavy traffic congestion. The extent to which these methods will actually contribute to the fight against smog in the city and whether Hangzhou will be able to comprehensively transform its transportation system, are issues which will have to be closely examined in the coming years. In the case of public "dialogue platforms" for industrial relocation, the punctilious, goal-oriented mobilization and inclusion of various political, social and economic interests was observable. As we showed, the local environmental bureaucracy was able to successfully employ public discontent to take action against SOEs within their jurisdictions. Here, as well, the long-term effects of these moves, including the conditions at the new industrial site, will need to be followed up. One of our core observations is that a "mixture of authoritarian and democratic features," which is, according to Bruce Gilley, common to "all environmental policy models," 65 was solely observable at the implementation stage, and only when it helped smooth or accelerate the process. This kind of governmental outcome orientation, and all the different forms of public inclusion and exclusion that it entails, still need to be given a greater emphasis in descriptions of a Chinese AE.

Ultimately, whether what is currently observable in China should be called "environmental-ism" at all, since this implies a universalist orientation and an over-prioritization of environmental goals over other goals, is, of course, highly questionable. What we can see, at the very least, is a remarkable environmental policy change, which reflects the accommodation, to a certain extent, of enormous public anxiety and mushrooming civil engagement, as well the acknowledgement of the health and economic risks posed by extreme air pollution, and which also entails considerable shifts in the interfaces and interactions of local governments, residents and the business/industrial sector. Nevertheless, as the term $\mathrm{AE}$ also suggests, this is all happening against the background of an authoritarian political system in China, where the CCP party state is not, of course, willing to relinquish its absolute monopoly over selecting, or at most tolerating, solutions as it sees fit.

\section{Acknowledgements}

Research for this article and the Airborne project was generously supported by the Research Council of Norway (grant no. 240060) and the Centre for Advanced Studies, Norway. The authors are furthermore grateful for invaluable support from colleagues at Zhejiang University, in particular, from Yi He, Yao Shi, Jianxing Yu, Yunheng Zhou and from other individuals in Hangzhou, such as Tao Feng, Liang Huang, Dimin Zhu and Hongjiang Pan. Of course, we are 
most indebted to all of our interviewees who offered their scarce time and rich insights. Finally, we thank the participants of the 2015 ASC conference at the University of Würzburg and of the 2016 AAS conference in Seattle for their helpful comments. All remaining errors are our own.

\title{
Biographical notes
}

Anna L. Ahlers is associate professor of modern Chinese society and politics at the University of Oslo, Norway. Trained in sinology and political science, her research interests include the administrative system and local governance in China, as well as the comparative analysis of value patterns and inclusion formulas in authoritarian regimes.

Yongdong Shen, formerly a postdoctoral researcher at the University of Oslo, Norway, is now a researcher at the School of Public Affairs at Zhejiang University, China. His current research focuses on the shifting role and strategic enforcement of Chinese local governments against the background of rapid economic transitions and the massive environmental pollution involved.

\begin{abstract}
摘要: 近年来, 中国政府采取了有史以来力度最大、措施最综合、考核最严 格的大气污染治理行动来应对严重的城市雾霧。这种自上而下限制产能、关 停污染企业等政策措施是否印证了威权式环境主义在中国的兴盛? 通过考察 杭州市大气污染治理的两种政策措施：机动车限牌限行与工业污染企业关 停搬迁, 我们探讨了中国地方政府在环境治理中所采取的不同执行策略及遵 循的执行逻辑。与既有“威权式环境主义”理论强调政策执行的“产出”有所 不同,我们发现,中国“威权式环境主义”更注重政策执行的“结果”。这在一定 程度上解释了为何中国地方政府在环境政策执行时表现出如此大的差异性 与灵活度。
\end{abstract}

关键词: 地方治理; 威权式环境主义; 大气污染治理; 机动车限牌限行; 工业 污染企业关停搬迁

\section{References}

Ahlers, Anna L., and Mette Halskov Hansen. 2017. "Air pollution: how will China win its selfdeclared war against it?" In Eva Sternfeld (ed.), Routledge Handbook of Environmental Policy in China. London: Routledge, 83-96.

Aunan, Kristin, Mette Halskov Hansen and Shuxiao Wang. 2017. "Introduction: air pollution in China." The China Quarterly, special section "Human dimensions of air pollution in China."

Beeson, Mark. 2015. "Authoritarian environmentalism and China." In Teena Gabrielson, Cheryl Hall, John M. Meyer and David Schlosberg (eds.), The Oxford Handbook of Environmental Political Theory. Oxford: Oxford University Press, 520-532.

Beeson, Mark. 2010. "The coming of environmental authoritarianism." Environmental Politics 19(2), 276-294.

Boren, Zachary Davies. 2015. "China Air Pollution. Things are getting better but $80 \%$ of cities are still super smoggy,” Greenpeace Energydesk, 15 October, http://energydesk.greenpeace.org/2015/10/15/ 
china-air-pollution-things-are-getting-better-but-80-of-cities-are-still-super-smoggy/. Accessed 16 October 2015.

Chen, Xiaojie, and Jinhua Zhao. 2013. "Bidding to drive: car license auction policy in Shanghai and its public acceptance." Transport Policy 27, 39-52.

Delman, Jørgen. 2014. "Climate change politics and Hangzhou's 'green city making'." In Per Olof Berg and Björner Emma (eds.), Branding Chinese Mega-Cities: Policies, Practices and Positioning. Cheltenham, UK: Edward Elgar, 249-261.

Delman, Jørgen. 2015. "Performance assessment, social accountability and sustainability governance in Hangzhou: leveraging the implementation gap?" Paper presented at the workshop on "Governance for urban sustainability in China: challenges and practices," University of Copenhagen, Denmark, 31 October-1 November 2015.

Feng, Suwei, and Li Qiang. 2013. "Car ownership control in Chinese mega cities: Shanghai, Beijing and Guangzhou.” Journeys (January), 40-49.

Gilley, Bruce. 2012. "Authoritarian environmentalism and China's response to climate change." Environmental Politics 21(2), 287-307.

Hangzhou City Environmental Protection Bureau (EPB). 2007. "Hangzhou shi Banshan diqu huanjing wuran zonghe zhengzhi gongzuo fang'an" (Scheme for the comprehensive regulation of environmental pollution in Banshan district).

Hangzhou City Environmental Protection Bureau (EPB). 2009. "Hangzhou shi Beidaqiao diqu huanjing wuran zonghe zhengzhi gongzuo fang'an" (Scheme for the comprehensive regulation of environmental pollution in Beidaqiao district).

Hangzhou City Environmental Protection Bureau (EPB). 2011. "Kuayue: Hangzhou shi huanjing wuran yonghe zhengzhi lichen" (Leap over: the progress of Hangzhou city's comprehensive regulation of environmental pollution [2007-2011]).

Hangzhou City Environmental Protection Bureau (EPB). 2013. "Changqun duihua: huanbao zhili de chuangxin pingtai" (Dialogue between polluting enterprises and local residents: an innovative platform for environmental governance). Hangzhou 254(3), 43-44.

Hangzhou City Environmental Protection Bureau (EPB). 2014. "2014 nian Hangzhou shi huanjing zhuankuang gongbao" (Environment Bulletin of Hangzhou city for the year 2014).

Hangzhou City Government. 2014a. "Guanyu yinfa Hangzhou shi daqi wuran fangzhi xingdong jihua (2014-2017 nian) de tongzhi” (Circular on the implementation of Hangzhou city's action plan for air pollution control and prevention [2014-2017]). 15 May. Document No. 80.

Hangzhou City Government. 2014b. "Hangzhou shi xiaokeche zongliang tiaokong zanxing guanli guiding" (Temporary regulations for control of the number of private cars in Hangzhou). 29 April. Document No. 7.

Hansen, Mette Halskov, and Zhaohui Liu. 2017. "Air pollution and grassroots echoes of "ecological civilization' in rural China." The China Quarterly, special section "Human dimensions of air pollution in China."

He, Baogang, and Stig Thøgersen. 2010. "Giving the people a voice? Experiments with consultative authoritarian institutions in China." Journal of Contemporary China 19(66), 675-692.

Kostka, Genia. 2016. "Command without control: the case of China's environmental target system." Regulation \& Governance 10(1), 58-74.

Kostka, Genia, and Sarah Eaton. 2014. "Authoritarian environmentalism undermined? Local leaders' time horizons and environmental policy implementation in China." The China Quarterly 218, 359-380.

Lewis-Beck, Michael S., Wenfang Tang, and Nicholas F. Martini. 2014. "A Chinese popularity function sources of government support." Political Research Quarterly 67(1), 16-25.

Li, Hongtao, and Rune Svarverud. 2017. "When London hit the headlines: historical analogy and the Chinese media discourse on air pollution." The China Quarterly, special section "Human dimensions of air pollution in China." 
Li, Xiaoyue, and Bryan Tilt. 2017. "Perceptions of quality of life and pollution among China's urban middle class: the case of smog in Tangshan." The China Quarterly, special section "Human dimensions of air pollution in China."

Luo, Sha et al. 2013. "Huanbao buzhang tan daqi wuran: "jiran tong huxi jiu yao tong fendou" (The Minister of Environment discusses air pollution: 'since we breathe together, we must fight together'), 15 June, http://news.sohu.com/20130615/n378878788.shtml. Accessed 26 June 2015.

Ran, Ran. 2015. Zhongguo difang huanjing zhengzhi: zhengce yu zhixing zhe jian de jilü (China's local environmental politics: discrepancies between policies and their implementation). Beijing: Zhongyang bianyi chubanshe.

Standing Committee of the People's Congress of Zhejiang Province. 2013. "Zhejiang sheng jidongche paiqi wuran fangzhi tiaoli" (Regulation for the control of motor vehicle exhaust pollution in Zhejiang province). 22 November. Document No. 8.

Sterner, Thomas, and Coria, Jessica. 2012. Policy Instruments for Environmental and Natural Resource Management. 2nd edition. London: Routledge/RFF Press.

Teets, Jessica C. 2013. "Let many civil societies bloom: the rise of consultative authoritarianism in China." The China Quarterly 213, 19-38.

Truex, Rory. 2014. "Consultative authoritarianism and its limits." Comparative Political Studies 50(3), 329-361.

Wang, Shaoguang. 2008. "Changing models of China's policy agenda setting." Modern China 34(1), 56-87.

Zhejiang Provincial Government. 2006. "Zhejiang sheng huanjing wuran jiandu guanli banfa" (Zhejiang provinces' supervision management measures for environmental pollution). 13 July. Document No. 321.

Zhejiang Provincial Government. 2010. "Zhejiang sheng xingzheng guifanxing wenjian guanli banfa" (Rules for the management of administrative regulatory documents in Zhejiang province). 20 July. Document No. 275. 